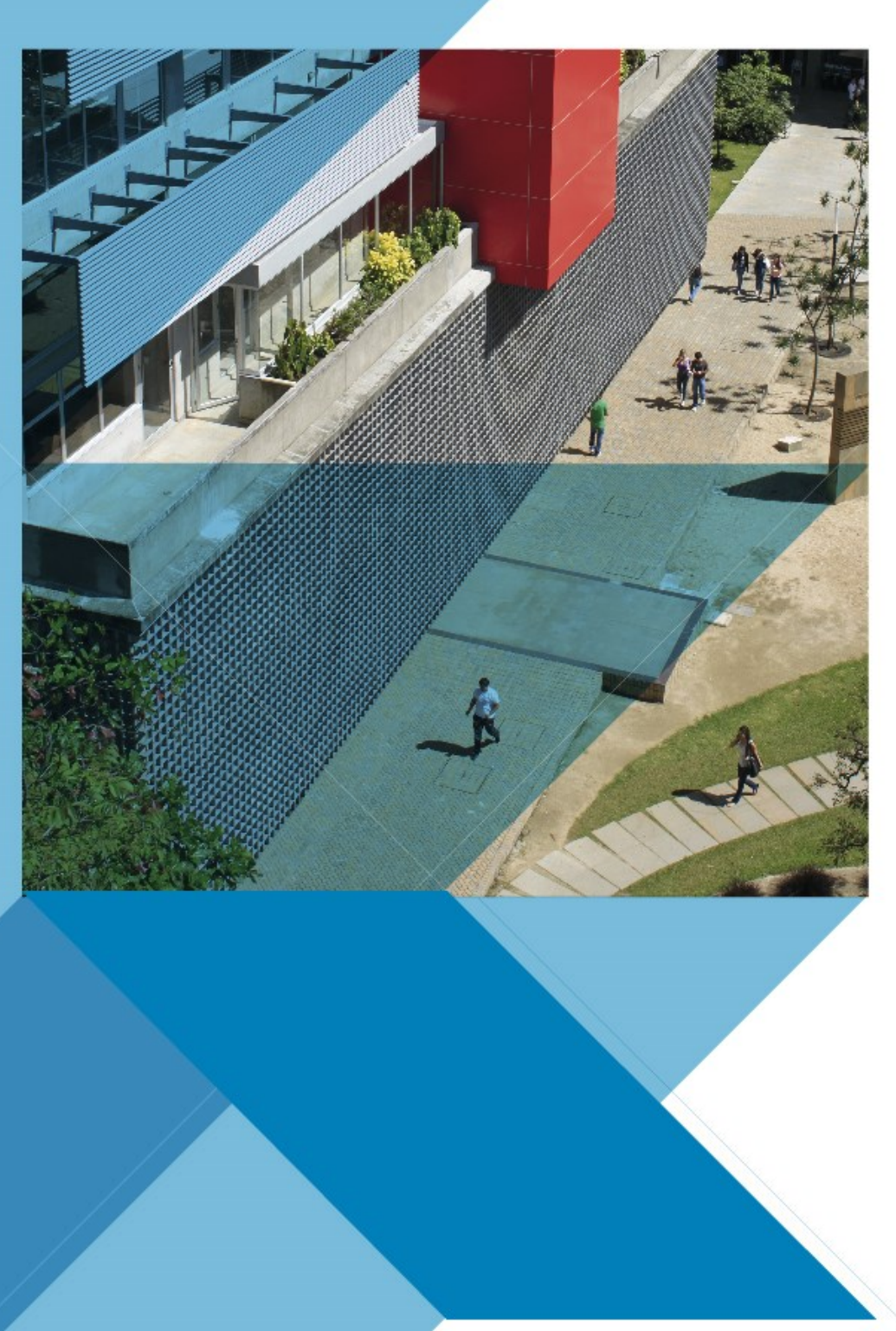

Escuela de Economía y Finanzas

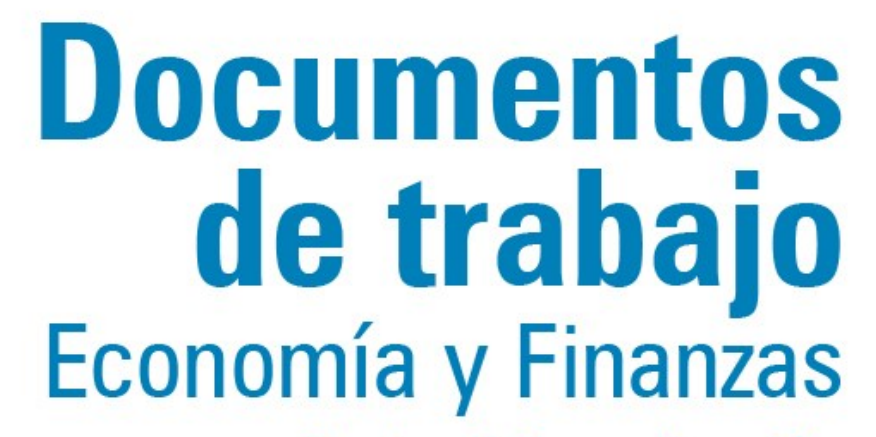

Centro de Investigación Económicas y Financieras

Who knows better in an Emerging Market?

No. 15-25 Performance of Institutions, Foreigners 2015 and Individuals.

Agudelo, Diego A. ; Byder, James E.; Yepes, Paula

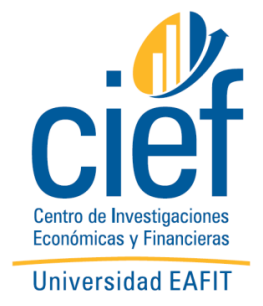




\title{
Who knows better in an Emerging Market? Performance of Institutions,
}

\section{Foreigners and Individuals.}

\author{
Diego A. Agudelo \\ dagudelo@eafit.edu.co*
}

\author{
James E. Byder
}

jbyder@eafit.edu.co

\author{
Paula Yepes
}

pyepes@eafit.edu.co

\begin{abstract}
We find that local investors do better than foreigners in terms of trading execution. However foreign investors obtain better returns than local individuals both in short and long term. Local institutions are the best group on both dimensions. Our result reconcile apparent contradictions in the international finance literature on who invests better in an emerging market. These contradictions disappears with a more careful formulation of the research question at hand. The traditional Locals vs Foreigners or Institutions versus Individuals is too simplistic because it doesn't distinguish between the different dimensions of performance. Our study makes use of two unique databases of Colombian stocks and acts as out-of-sample test of previous findings. Moreover, we provide evidence that the better performance of Institutions and Foreigners is driven by information advantages.
\end{abstract}

JEL: G14, G15, D82

Keywords: Institutional investor, foreign investors, individual investors, Informed trading, bid-ask spread decomposition.

All authors: Finance department. Universidad EAFIT. Carrera 49 No. 7 Sur 50. Medellín, Colombia. Phone (574) 2619500 ext. 9719. *Corresponding author.

This article originated was funded by a research grant from Universidad EAFIT. We acknowledge useful suggestions from Jairo J. Agudelo and Mateo Vasco. We are also grateful to Adriana Cardenas, from Bolsa de Valores de Colombia for providing the data, and David Arango and Camilo Silva for collecting the transaction database. All errors remain our own responsibility. 


\section{Introduction}

Classical asset pricing models assume agents in financial markets are homogeneous. Market microstructure models in turn differentiate between informed and uninformed investors. Such models provide a role for each type of investor in the process of information revealing, and price and liquidity formation. Accordingly, the literature on investments has devoted much thought to the differential roles, behavior and effects of different types of investors. Emerging Markets provide particular value for studying the performance of foreigners and locals due to their lower levels of development in terms of liquidity, trading activity, transparency and efficiency. In principle, it's not obvious whether foreigners or locals should be better investors. In one sense we could expect foreigners to perform better due to deeper pockets, access to more sophisticated research, greater trading experience amongst other. In another sense a home advantage would give locals access to different and perhaps more valuable sources of information

The empirical literature has been ambiguous. Grinblatt and Keloharju (2000) reported that foreigners in Finland perform better, proposing superior information as the probable cause. Huang and Shiu (2009) find that Taiwanese stocks with high foreign ownership outperform stocks with lower foreign ownership. The authors argue that this is consistent with foreigners having a greater information advantage over locals. Ferreira, Matos, \& Pereira, (2009) find foreign money managers perform better than local managers which they put down to greater acces to knowledge, skills and learning opportunites. On the other hand, there is mounting evidence of locals having superior performance to foreigners. Brennan and Cao (1997), for example, looking at portfolio investment flows between the US and four developed countries, find that locals have an advantage. Hau (2001) compares the performance in German stocks of professional traders located in and outside Germany, again showing that locals have a better investment performance. In emerging markets, 
a number of recent papers show that locals perform better (see e.g. Agarwal, Faircloth, Liu and Rhee, (2009) and Dvořák (2005) for Indonesia, Chan, Menkveld, \& Yang (2008) for China, and Choe, Kho, \& Stulz (2005) for Korea). Moreover, in the context of financial crises several studies report that locals better anticipated crashes than foreigners (See e.g. Kim and Wei (2002) and Kaufman, Mehrez and Schmuckler (2005)). The evidence thus appears mixed.

It is our contention that the debate on locals vs foreigners and Institutions versus Individuals has been misrepresented. As mentioned above, a sizeable number of authors suggest that locals perform better while a similar number of academics have concluded the opposite We believe that this apparent contradiction stem from imprecise definitions of our investor groups and a lack of depth in the performance definition. With a more careful articulation of the performance results and the investor categories it becomes evident that much of the apparent contradiction in the literature disappear. In such circumstances the conclusions of the vast majority of authors are entirely compatible. The problem stems from the fact that literature has traditionally posed the research question as foreigners versus locals but this comparison is not fair or appropriate. This is because most foreigners reported in previous studies are actually institutions so one is not really comparing like for like. Moreover, 'locals' means very different things in a developed stock market than in an emerging one. In developed markets our domestic investor group normally used to proxy locals is most heavily comprised of institutions. In contrast domestic investors in emerging markets are most heavily comprised of local individuals. For example local individuals make up between $60-75 \%$ of the trading value in Korea (Choe et al., 2005) and 90\% in Taiwan (Barber, Lee, Liu and Odean, 2009). In the database used in our study, the size of local individual trading is not quite as high as in the Asia however still significantly larger than in developed markets. For example, Colombian individual investors represent $36 \%$ of the traded value, with institutions comprising 
$52 \%$ and foreigners the remaining $11 \%$. In a typical developed market the size of the local investor group is usually much smaller. For example, in a sample of NYSE stocks, Kaniel, Saar, \& Titman (2008) report that Individual are responsible of about the $4 \%$ of the weekly trading value. For these reasons, the traditional debate of foreigners versus locals could be considered misleading. Two more meaningful comparisons would be between local institutions versus local individuals on the one hand, and local institutions and foreign institutions on the other hand.

To the extent of our knowledge, only three studies have contrasted the differences in performance between the three investors groups. Choe et. al (2005) in Korea, find both that domestic money managers obtain better execution prices than foreign institutions and that domestic individuals trade at better prices than foreign institutions. They discard explanations of price impact and information, instead offering return chasing by foreigners as a possible reason. On the contrary, Barber et al (2009) using transactions data from Taiwan find that individual investors systematically underperform both local and foreign institutions. Local institutions have the best performance of the three groups in both aggressive and passive trades. Finally, Lee, Liu, Roll, \& Subrahmanyam (2004) using intraday data from Taiwan, study the order imbalance and net order flow of the three types of investors. They find that large domestic institutions are responsible for most of the informed trading while large individuals tend to be noise traders or liquidity providers.

We contribute to this literature for two main reasons: First, we are able to replicate and check several of the results of the previous literature in a new country, Colombia, whose stock market is highly representative of small size emerging markets. This is the first article exploring the question of investor performance in Latin America with most previous emerging market studies focusing on Asia. Our study makes use of a unique and detailed database from the Colombian Stock Exchange (BVC) that compiles buys and sales of every Colombian stocks on a daily basis. 
Investors are split between foreign, individual and institutional, with Institutional Investors broken down into various sub categories. Our data spans more than seven full years. By estimating different performance measures by type of investor, we are able to implement an out-of-sample test of the most important results identified in the previous literature. Our results allow us to reconcile the apparently contradictory results to which we refer above.

Second, we go beyond the previous literature by providing evidence of a link between shortterm performance and information advantage. Market microstructure models such as Hasbrouck, (1991) and Kyle (1985) formalize a relation between informed trading and decreased liquidity, usually measured as increasing bid-ask spreads. Other studies provide supporting evidence of this relationship ( see e.g. Easley, Engle, O’Hara, \& Wu, 2008; Easley, Hvidkjaer, \& O’Hara, 2010; Lei \& Wu, 2005) including one Latin American study that incorporates Colombian stock data (Agudelo, Giraldo, \& Villarraga, 2015). Some of those models imply that superior information should move prices in the direction of the information (Easley \& O'Hara, 1992; Glosten \& Milgrom, 1985; Kyle, 1985). Furthermore, several studies propose methodologies that extract the bid-ask spread component related to adverse selection (Huang \& Stoll, 1997; Jong, Nijman, \& Rsell, 1996; Madhavan, Richardson, \& Roomans, 1997). In our paper, starting with trade and quote data, we use the spread decomposition model of Madhavan, Richards \& Roomans (1997) (henceforth MRR) to estimate the adverse selection component of the bid-ask spread on Colombian stocks during a period of two years. This serves as a measure of informed trading. It enables us to test for a direct relation between trading intensity of each group of investors and informed trading. Depending on whether these results align with those of short-term performance, it could support the hypothesis of a group of investors obtaining better returns by exploiting an information advantage 
Our main results can be synthetized as follows. First, we provide evidence that both local individuals and institutions have a trade execution edge over foreigners, by trading at more favorable prices. This is consistent with the findings of Choe et al.(2005) in Korea. Moreover, different short-term and long-term performance measures indicate that local institutions are more effective traders than foreigners who in turn are more effective traders than local individuals. Our results reconcile the apparently contradictory findings of previous papers which have indicated a local advantage (Agarwal et al., 2009; Brennan \& Cao, 1997; Dvořák, 2005; Hau, 2001), versus those concluding the opposite (Ferreira, Matos, \& Pereira, 2009; Grinblatt \& Keloharju, 2000; Huang \& Shiu, 2009). In addition, we are able to reconcile the apparently contradictory results of Choe et al (2005), who report an advantage of local individuals over foreigners, with Barber et al (2009) who suggest the opposite. The difference occurs because Choe et al (2005) measures trade execution, whereas Barber et al (2009) compare long term performance. We are able to replicate both results and find that both conclusions are valid and entirely consistent with one another. Moreover, we are able to provide evidence of the information advantage of both institutions and foreigners over individuals. Specifically, after applying the MRR spread decomposition model, we find a relation between institutional and foreign trading and the adverse selection component of the bid-ask spread. The effect is larger for institutions. Thus, this evidence is consistent with Institutions, and to some extent foreigners, exploiting an information advantage to obtain superior short-term performance.

The two most related studies to our paper are Barber et al. (2009) in Taiwan and Choe et al. (2005) in Korea. Both compare the performance of the three type of investors. Our study differentiates from both papers in at least two aspects. First, by applying a spread decomposition model, we provide evidence of a relation between superior performance from institutions and 
foreigners with informed trading. This relation between information and short-term performance, is consistent with the predictions of the different market microstructure models of Glosten and Milgrom (1985) and Kyle (1985). Second, our study includes both trade execution and short and long-term performance of the different types of traders, and measures them independently and jointly. The previous two studies focus only on one of them. This is not a small detail, since the sizable average execution advantage that locals have over foreigners, as reported by Choe et al. (2005), could explain their differential performance.

Our paper is organized as follows: Section 2 describes the two unique databases used in this study. Section 3 describes the methodology, providing details of the different measures of performance employed. Section 4 presents and discusses the results of differential performance in the short and long term, and the differential effects on informed trading. Finally, section 5 concludes.

\section{Data}

We take advantage of a unique database from the Colombian Stock Exchange (BVC), as described in Table 1 . This database summarizes information on daily buys and sells by different types of investors for each stock traded on the BVC from 1-Jan-2007 to 15-May-2014. Buys and sells are measured in number of operations, traded value and traded volume. Type of investors include Local institutions, Foreigners and Local Individuals. Local institutions include Brokerage Firms, Pension Funds, Mutual Funds, Trusts, Corporations, and Banks and other financial institutions. For our purposes we group together all types of local institutional investors. As mentioned above, and verified by the Stock Exchange and two major Colombian brokerage houses 
(source). Foreigners are mostly institutions, typically International Mutual and Hedge Funds. For each stock-day and each type of investor, the database reports value weighted average price, traded volume (number of stocks), trading value in U.S dollars and number of operations, separately for buys and sells. This information is summarized in Table 1 by quartiles of market capitalization. BVC generates this database from the stock exchange transaction, that include identification for both parties in each trade and allows then to classify both in the various groupings based on the unique tax number (NIT).

Table 1 present some interesting differences. In the overall sample, Institutional investors do most of the trading in terms of money, $53 \%$ for the total sample, against $11 \%$ for foreigners and $36 \%$ for individuals. Institutions are responsible for more than half of the trading value for the three top size quartiles, only overpassed by individuals in the bottom quartile. This higher role of individuals in trading smaller stocks is consistent with the US market ( Barber, Odean, \& Zhu, (2008)). Foreign investors, in turn, have the smallest share of the trading value in all quartiles, which coincides with those reported for Indonesia (Dvořák, 2005), Korea (Choe et al., 2005), and Taiwan (Barber, et al., 2006). When trading activity is measured by number of trades, institutions and individuals change places. In this case individuals are responsible for more than half the number of trades in every quartile, reaching about $68 \%$ in the bottom quartiles. Such a pattern is similar to the one reported in the mentioned studies of Indonesia, Korea and Taiwan. When estimating the daily average trading size, a familiar pattern also emerges. Institutional investors have the largest trades on average, closely followed by foreigners, for the whole sample and in each size quartile except the lowest one. Individual investors in contrast present average trade sizes 3 to 2 times lower than the other two groups. 
We perform the following adjustments to the data. First, in the original BVC database we verify the balance between stocks bought and sold on each stock day. We do this for traded value and number of shares and number of operations. We find only very minimum discrepancies in the balances. Second, since the BVC database reports historical prices, we calculate the adjustment factors required to properly account for splits and dividends paid in stocks. Third, we decide not to take into account the trading activity of the "ADRs" group. Colombia has four stocks listed as ADRs type II or III, all of them in the NYSE. ADR trades are performed by Brokerage Firms, acting on behalf of ADR investors typically as part of arbitrage operations between the ADR and the underlying local stock. Since we are unable to classify those trades as belonging to institutions, foreigners or locals we decide to omit them from our analysis. . They comprise just below $0.011 \%$ of the trading value of the individual underlying stocks and about $0.002 \%$ of the overall trading value on the stock exchange.

In order to test for informed trading in a market microstructure setting, we collect from Bloomberg a trade and quote database for Colombian stocks, for the period 23-August 2010 to 31August $2012^{1}$. This database is made up of the time-stamped trades and quote revisions for the 42 most traded stocks in Colombia. Stocks in the Colombian stock exchange (BVC) trade in a pure limit order book market, without designated market makers or dealers. Furthermore, the market operates most of the time as a continuous market, but closes in a call auction that lasts approximately 5 minutes. An additional feature of the Colombian stock market, are circuit breakers that from time to time interrupt the continuous market ("volatility call auctions"). Circuit breakers are triggered by sharp price movements and lasting a few minutes. Since spread decomposition

\footnotetext{
${ }^{1}$ Bloomberg only stores 6 months of trade and quote data, so this database had to be hand collected through a period of two years.
} 
models are based on a continuous market, we remove the trades and quote revisions that correspond to both closing and "volatility" call auctions ${ }^{2}$, After cleaning the data we end up with a total of approximately 740.000 trades and around 3 million of quote revisions. To implement the MRR decomposition model as applied in Ahn, Cai, Hamao, \& Ho (2002), we classify each trade as a buyer or sell initiated using the algorithm of Lee \& Ready (1991).

\section{Methodology}

\subsection{Performance measures by Investor group.}

We measure the performance of the different types of investors in three dimensions: trade execution, short-term performance and long-term performance.

To measure trade execution we estimate the average execution cost separately for buys and sells. Specifically, we calculate the proportional difference for each type of investor " $j$ " of the value weighted average trading price for buys (sells) with the value weighted average daily price (VWAP) of the stock " $i$ " in day " $t$ " as follows:

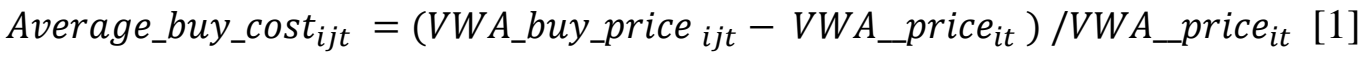

$$
\begin{aligned}
& \text { Average_sell_cost }_{i j t}=\left(V W A \_p r i c e_{i t}-V W A \_s e l l \_p r i c e{ }_{i j t}\right) / V W A \_p r i c e_{i t}[2]
\end{aligned}
$$

Since we are accounting for both sides of each trade in any given stock-day (with the noted exception of the ADRs) the average costs should add up close to zero among the type of investors. A positive average buy or sell cost can be interpreted as aggressive trading for exampling posting

\footnotetext{
${ }^{2}$ these are identified from a database provided by BVC.
} 
mostly market or marketable limit orders, or creating price impact by demanding liquidity beyond the bid/ask depth. To some extent, this could also be due to prices moving against the trade as in Choe, Kho, and Stulz (2005). Conversely, a negative average buy or sell cost means less aggressive trading, supplying liquidity with limit orders and/or implementing strategies to minimize price impact.

Short-term (daily) performance is measured with three measures. First a very simple measure takes the next-day return of stock " $i$ " (the negative of it) if the type of investor " $j$ " had a positive (negative) net total buy in the current day " $t$ ", as follows:

$$
N e x t \_d a y \_r e t u r n_{i j t}=\operatorname{sign}\left(N e t_{-} b u y_{i j t}\right) \times\left(\frac{V W A_{-} \text {price }_{i t+1}}{V W A_{-} \text {price }_{i t}}-1\right)
$$

With $N_{e}{ }_{-} b u y_{i j t}=Q_{-} b u y_{i j t}-Q_{-} s e l l_{i j t}$, the differences in quantities bought and sold by the type of investor on the current day.

Whereas [3] is a straightforward measure of short-term performance, it doesn't take into account the magnitude of the net buy. We propose a net profit measured, roughly following Dvořák (2005), based on the next-day increase in value of the position of a type of investor " $j$ " due to the net buy on day " $t$ " and the price increase in " $t+1$ ". We normalize it with the average trading value per type of investor, as follows:

$$
N e t \_p r o f i t 1_{i j t}=\frac{\left(Q_{-} b u y_{i j t}-Q_{-} \text {sell }_{i j t}\right) \times\left(V W A_{-} \text {price }_{i t+1}-V W A_{-} \text {price }_{i t}\right)}{\text { Average_trading_value }_{i j}}
$$

With Average_trading_value $e_{i j}=\frac{\sum_{t=1}^{T}\left(Q_{-} b u y_{i j t} \times V W A_{-} b u y_{-} \_r i c e_{i j t}+Q_{-} \text {sell }_{i j t} \times V W A_{-} \text {sell_price }_{i j t}\right)}{T}$

Measure [4] captures the profit coming from both buying a stock that increases in price at the next day, and by selling a stock that decreases. However it doesn't incorporates the effect of 
differential trade execution among the three types, since it assumes that buys and sells are made at the same daily price, $V W A_{-}$price it $_{\text {. In }}$ Inesponse, we propose the following alternative measure that takes into account the specific execution prices by type of investor:

$$
\begin{aligned}
& \text { Net_profit } 2_{i j t}=
\end{aligned}
$$

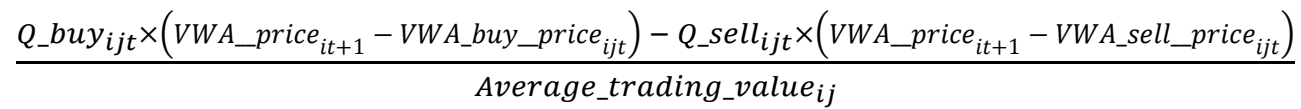

As a result, measure [5] incorporates both the short-term performance of [4] and the execution cost effect of [1].

The measures presented above focus on one-day performance, which might be related only to short-lived information. In order to measure monthly performance, we form portfolios of stocks that reflect the preferences of institutions, foreigners and individuals, loosely following Barber, Odean, and Zhu (2008). Specifically, at the end of each month we rank stocks depending on the monthly net buy for each type of investor, and form equally weighted portfolios accordingly. For instance, portfolio $Q 4 \_n e t b u y_{j t}\left(Q 1 \_n e t b u y_{j t}\right)$ is an equally weighted portfolio of the stocks most bought (sold) by type of investor " $j$ " in month " $t$ ". We estimate the return of this portfolio in month " $t+1$ ", and rebalance it at the end of month " $t+1$ ". Thus, these portfolios represent a way to implement a strategy that use the information content of net buys by type of investors, and to measure performance. On the one hand, it's expected that the Q4_netbuy ${ }_{j t}$ outperform the corresponding $Q 11_{-} n e t b u y_{j t}$ if the type of trader " $j$ " has any stock picking abilities. On the other hand, their returns provide a measure and comparison of the overall stock picking abilities of the different type of investors. 
In a similar fashion, to estimate the one-year performance we take the same portfolios based on monthly net buy by investor, described above, and estimate their return in the 12 -month period following the month, with no rebalancing during that 12-month period. Since there is overlapping between portfolios within a 12 month span, they can't be considered as return of the same strategy,

unlike the one-month returns. Anyway, the raw returns of those portfolios provide a way to measure the long-term performance of each type of investor.

\subsection{Informed trading effects by investor group}

As mentioned above, we search for evidence of the link between information and performance. In market microstructure models informed trading can be detected by its effects on the bid-ask spread (Easley \& Hara, 1992; Easley et al., 2008; Lei \& Wu, 2005; Agudelo et al., 2015). We use the MRR model, to perform a decomposition of the spread in the trade and quote database of Colombian stocks mentioned above. This model has been previously used in electronic order-book markets, as in Japan (Ahn et al., 2002) and more recently in the Euro-Dollar spot market ( Chen \& Gau, 2014), the Korea Stock Exchange (Eom, Ok, \& Park, 2007), and the market for interest rate futures in Mexico (Bowe, Hyde, \& Mcfarlane, 2013). Specifically the MRR decomposition model, as implemented in Ahn et al. (2002) estimates the implicit bid-ask spread components based on the change on transaction prices, in the following model:

$$
\Delta P_{t}=\alpha\left(Q_{t}-\rho Q_{t-1}\right)+\beta\left(Q_{t}-Q_{t-1}\right)+u_{0}+u_{t}
$$

Where $\Delta P_{t}$ is the change in consecutive transaction prices, $Q_{t}$ is a buy-sell trade identifier, equal to $1(-1)$ if the trade was buy-initiated (sell initiated), $u_{0}$ is a constant drift, and $u_{t}$ is the disturbance term. Parameter $\rho$ is the autocorrelation between identifiers of successive trades, rendering $\rho Q_{t-1}$ 
as the expected sign of transaction " $t$ ". In turn, $\alpha$ measures the part of the bid-ask spread associated to the revision in expectations, this is, the adverse selection component, and $\beta$, is the change in price due to bid-ask bounce, revealing the component of the spread associated to liquidity supply: the inventory and order processing costs. Thus $\alpha+\beta$ is the estimation of the implied spread. Model [6] is estimated by means of a GMM procedure ${ }^{3}$.

Since we are interested in the time variation of the spread components to relate it with the trading activity of the different investor groups, we estimate [6] in a stock-week basis. Due to insufficient trading activity the model cannot be estimated in all the cases. At the end, the model was estimated in 3,188 stock-weeks, from about 30 stocks in 105 weeks.

To test whether foreigners or institutions are associated to increased informed trading, we regress the estimated implied spread $(\alpha+\beta)$ and the adverse selection component $(\alpha)$ against measures of trading intensity of the two groups, controlling for known determinants of the spread, as follows:

Implied_spread $_{i t}=$ Volat $_{i t}+$ Log_num_op $_{i t}+$ return $_{i t}+\log _{-}$Price $_{i t}+$

$$
\log _{-} \text {Avg_trade_Size } e_{i t}+\text { Foreign_trad }_{i t}+\text { Inst_trad }_{i t}
$$

$$
\begin{aligned}
& A d v_{-}{ }_{\text {selec_comp }}{ }_{i t}=\text { Volat }_{i t}+\log _{-} n u m_{-} o p_{i t}+\text { return }_{i t}+\log _{-} \text {Price }_{i t}+ \\
& \log _{-} A v g_{-} t r a d e_{-} S_{i z e}+\text { Foreign_trad }_{i t}+\text { Inst_trad }_{i t}
\end{aligned}
$$

Following similar models in the literature (for example, De Cesari, Espenlaub, \& Khurshed, 2011; Grullon, Kanatas, \& Weston, 2004a; Hendershott \& Moulton, 2011) we include as control

\footnotetext{
${ }^{3}$ The GMM procedure is estimated with the following four moment restrictions: orthogonality between the revision in the identifier and its previous value: $Q_{t-1}\left(Q_{t}-\rho Q_{t-1}\right)=0$; the zero mean of the disturbance: $u_{t}-u_{0}=0$; and the orthogonality conditions between the disturbance and the identifiers on $t$ and on $t-1: Q_{t}\left(u_{t}-u_{0}\right)=0$, $Q_{t-1}\left(u_{t}-u_{0}\right)=0$
} 
variables the volatility of the stock as the standard deviation of the change of prices each five minutes $\left(\right.$ Volat $\left._{i t}\right)$, the log of the number of operations as a measure of trading activity, $\left(\log _{-} n u m_{-} o p_{i t}\right)$, the return of the stock $\left(\right.$ return $\left._{i t}\right)$, the log of the price $\left(\log _{-} P r i c e_{i t}\right)$, and the log of the average trade size $\log _{-} A v g_{-} t r a d e_{-} S_{i z e}$. As variables of interest we include the proportion of value traded by Foreigners and Institutions in a given stock week, Foreign_trad $i t$ and Inst_trad $i t$, respectively.

\section{Results}

\section{$\underline{4.1 \text { Differential short-term performance }}$}

We start by investigating the differential short-term performance of the three types of investors: local institutions, foreigners and individuals. Table 2 presents the results of the average trading cost in both buys and sells by the three types of agents, for the whole sample and four quartiles of size. Interestingly, individuals achieve the best execution of all, with statistically significant negative average cost all across the quartiles, and particularly large savings in purchases, with an average cost of $-0.1 \%$. Institutions are second, also with significantly negative average costs in buys and sells, the largest average savings in sells, and significantly negative selling cost for each size quartile. Local institution's cost savings only disappear for the buys in the two bottom size quartiles. In stark contrast, buys and sell by foreigners have the largest average cost for every size quartile. Since by definition measures [1] and [2] are zero-sum in each stock-day, we can say that average savings by institutions and individuals occur at the expense of Foreigners. Taken together these findings with those of average trading size in Table 1, in absence of more detailed data, are consistent with foreigners trading at a disadvantage with locals. This is in part due to their larger 
trading sizes, individuals having less price impact (and perhaps more of the liquidity providing), and institutions being particularly efficient at trading execution, in spite of their large average trades. These results can be interpreted as Individuals and Institutions being more cautious traders than foreigners and coincide with the findings of Choe et al., (2005) in Korea and Agarwal et al., (2009) in Indonesia.

Table 3 present the results of the simple daily performance measure [3] for the three types of investors, for the overall sample and the four quartiles of size. None of the three types have a daily performance significantly different from zero for the whole sample. However, both Institutions and Foreigners have a positive and statistically significant performance in the top size quartile, and Foreigners also have it in the third quartile. In contrast, individuals have a negative performance in the two top quartiles of size. Since daily average returns for stocks are not significantly different from zero, average performance [3] should be around zero each stock-day, a positive performance of institutions and foreigners is linked to the negative one of individuals. Thus, these findings suggest that, for the larger stocks, Institutions and Foreigners tend to buy (sell) before next-day stock price rises (drops), whereas Individuals do the opposite. In principle, this is consistent with an information disadvantage of Individuals relative to the other two types. Yet, this is only a indicative result since measure [3] is too simple to capture the diverse aspects of performance.

Net profit measures [4] and [5], unlike [3], do take into account the net buy of each of the three investors in day $t$ and the return in day $t+1$, with [5] also incorporating the price execution in day $t$. The results of Net profit 1 [4] are presented in Table 4, portraying a superior performance of Institutional investors in the overall sample, with positive and statistically significant net profit as well as in quartiles 4 and 2, and positive performance, marginally significant, in the lowest quartile. Foreigners in turn present an overall performance not statistically different from zero, with the only 
exception of a positive net profit measure in the third quartile. Individuals, in turn, have a significant negative performance overall and in every quartile. This outcome is qualitatively similar to that of the simple daily measure [3] in Table 4, with individuals trading at a disadvantage with local and foreign institutions, very much as reported in Taiwan (Chen, Lin, Ma, \& Zheng, 2013; Lee et al., 1999) and Korea (Park et al., 2014).

The results of Net Profit 2 [5] are presented in Table 5. Net profit 2 can be seen as a refinement of the daily performance measure Net profit 1 that incorporates the trade execution cost [1] and [2] presented in Table 2. As expected, the average performance of Institutions in the whole sample is superior to the one in Table $4(0.04 \%$ vs. $0.03 \%)$, associated with their negative execution costs both at buys and sells in Table $2(-0.01 \%$ and $-0.03 \%)$. Moreover, this positive performance of institutions is statistically significant for the whole sample and the top three size quartiles. Foreigners in turn, have a significantly negative performance in the overall sample $(-0.27 \%)$, contrasting with the respective of Net Profit $1(0.03 \%)$ but clearly explained by the execution cost in both buys and sales reported in Table $2(0.09 \%$ and $0.07 \%)$. Finally, individuals have a negative overall performance $(-0.02 \%)$, slightly inferior to the one in Table $4(-0.03 \%)$, due to their negative execution cost in Table 2 (-0.01\% for buys and $-0.03 \%$ for sales). Still, individuals have negative and statistically significant performances overall and in the quartiles 4 and 2.

Taken together, the results in Tables 3 to 5 show that local institutions have better daily performance than the other two types, tending to execute larger net buys (sells) in stocks with positive (return) at the next day, and benefitting with a better trade execution. This confirm the result in Table 3. In turn, Foreigners appear as average performance investors, with a performance before costs not different from zero, which is made negative by their larger trading costs. Finally individuals, have the worst performance of the three types, tending to have larger net buys (sells) 
in stocks with negative (positive) return in the following day. Their negative performance is somewhat mitigated by their favorable execution costs. This superior short-term performance of Local Institutions over Foreigners and Individuals might be connected to an information advantage, which will be tested in a market microstructure model.

\subsection{Differential Long-term performance}

Table 6 summarizes the performance of the portfolios of the most bought stocks (Q4_netbuy $\left.y_{j t}\right)$, and most sold stocks $\left(Q 1 \_n e t b u y_{j t}\right)$ by each of the three type of investors, estimated from the monthly total net buy and recomposed monthly, as described in the Methodology section. We also include a $Q 4-Q 1 \_n e t b u y_{j t}$ portfolio, long in the most bought stocks and short in the most sold ones. Panel A presents the summary statistics of the monthly returns and compares it with returns of the corresponding portfolios for the other types. Panel B shows the alfa and beta from a market index model, that regress the excess return of each portfolio against the excess return of the COLCAP. Finally, Panel C exhibits the summary statistics of the 12-month returns of the portfolios and the statistical comparison the corresponding portfolios of the other types.

Panel A of Table 6 indicates that the portfolios $Q 4 \_n e t b u y_{j t}$ and $Q 4-Q 1 \_n e t b u y_{j t}$ of Institutions render a positive and statistically significant return at $10 \%$ level, pointing to a superior performance of those investors. For Foreigners and Individuals only Q1_netbuy ${ }_{j t}$ portfolio delivers a statistically significant return but positive, suggesting deficient stock-picking by those investors, since the stocks they sell the most have a positive return in average, even above those they buy the most, as implied by the negative average returns of the $Q 4-Q 1 \_n e t b u y_{j t}$ portfolios. Moreover, the results of the $t$ test in Panel A show that the Institutional Q1_netbuy $y_{j t}$ portfolio 
renders a statistically lower return that those for Foreigners and Individuals. Additionally, the Institutional $Q 4-Q 1 \_n e t b u y_{j t}$ portfolio has a higher average return that those for the other two types. Consistently, the results in Panel A indicate a superior one-month performance of Institutions, and inferior for Foreigners and Individuals.

Of course, the superior stock picking of Institutions over the other two types might be well due to differences in systematic risk. However, the estimations of Jensen's Alfa presented in Panel B reveals that this is not the case. Institutions hold the only significantly positive alfa for the Q4-Q1_netbuy ${ }_{j t}$ portfolio, the higher alfa for the $Q 4 \_n e t b u y_{j t}$ portfolio, and the lower for the Q1_netbuy ${ }_{j t}$ portfolio. On the other hand, the results of one-month performance don't deliver any difference between foreigners and individuals ${ }^{4}$

So far we have found the Institutions consistently beating both Foreigners and Individuals at daily and monthly frequency. But, is this advantage short lived?. To answer that we estimate and compare the 12-month average return of the portfolios, as presented in panel $\mathrm{C}$ of Table 6 . Interestingly, Q4_netbuy $y_{j t}$ portfolios for Institutional and Foreign investors deliver a positive and highly significant 12-month return, both of them statistically higher to the one of Individuals. In turn, the $Q 11_{-}$etbuy $y_{j t}$ portfolios for Institutions and Foreigners deliver a return significantly below the one of individuals. Moreover, the $Q 4-Q 1 \_n e t b u y_{j t}$ portfolio for institutional investors deliver statistically higher return that the one of Foreigners and that in turn do the same to the one

\footnotetext{
${ }^{4}$ These results are confirmed when regressing together in a SUR model the excess returns of each group of three portfolios (unreported), to test the statistical significance of the difference between the alfas. We found that, the Q1_netbuy $y_{j t}$ portfolio for Institutions is significantly lower than the alfas for the other two, and that the alfa for Q4 - Q1_netbuy ${ }_{j t}$ of Institutions is significantly higher than the one for Individuals.
} 
of Individuals. Overall those findings reflect a superior one-year performance of the stocks preferred by Institutions, an intermediate for Foreigners and the inferior for Individuals.

Summarizing the results of Table 6, Institutional investors as a group show the best ability at choosing stocks compared to Foreigners and Individuals, measuring performance in periods of one and twelve months. This result is more driven by the stocks Institutions avoid or sell the most than by those they tend to prefer. In turn Foreigners, while showing a comparable ability to Individuals, when performance is measured in one month, deliver a superior performance when measured in one year. These results are similar to the ones obtained in previous studies comparing the performance of the same three groups of investors in Taiwan by Barber et al., (2009). The authors argue that the lower performance of individuals can be explained by aggressive orders. In contrast, our results point to an inferior stock picking ability, especially in the stocks they sell the most.

\subsection{Differential Informed trading effects}

Here, we explore whether the variation of short-term performance across investor groups can be related to differentials in informed trading effects. As described above the MRR model offers a way to extract the adverse selection cost component of the bid-ask spread apart from order processing costs. If a particular group of investors had information advantage that should be reflected in higher adverse selection cost component in days when they trade the most. We are able to test this hypothesis by estimating models [7] and [8] on the implied spread and the adverse selection component of the spread calculated with the MRR model, controlling for other known determinants of the bid-ask spread. 
Panel A of Table 7 presents the results of two fixed-effects panel data models that regress the implied spread and its adverse selection component, estimated in a stock-week basis, against determinants of the bid-ask spread, and include two variables Foreign_trad ${ }_{i t}$, and Instit_trad ${ }_{i t}$ that measure the trading intensity by foreigners and local institutions, respectively. As expected we obtain a negative and marginally significant relation between the implied spread and both trading activity $\left(\log _{-} n u m_{-} o p_{i t}\right)$ and stock return $\left(\right.$ return $\left._{i t}\right)$. Besides, since we are modelling the bid-ask implicit spread rather than the proportional spread, there is a strong relationship between price and the implied spread. All those relations have been reported by the literature in similar models (see for example Grullon et al., 2004; Agudelo et al., 2015). More interestingly are the results in the adverse selection component. We find both positive and statistically significant effects from the Foreign and the Institutional trading intensity, which are consistent with the trading of both groups of investors increasing the adverse selection cost over and above the trading of Individuals. Finally, although the coefficient of Institutions is somewhat larger than for Foreigners, when we perform a Wald test between the coefficients of Foreign and Institutional trading we find no statistically significant difference.

On the other hand, regressing the implied spread and its adverse selection components disregards that both variables are dependent between them. To address that potential criticism, we estimate a Seemingly unrelated regression (SUR) model that estimates simultaneously equations [7] and [8], as presented in Panel B of Table 7. The results of the implied spread equation are qualitatively very similar to those of the panel data. The results for the adverse selection component are somewhat different from those in the panel data. The trading activity coefficient switches its sign, but no so those of the return and price. Notwithstanding, the coefficients of both foreign and local trading intensity remains positive and gain in statistical significance. In this model we find 
that Institutions have more than double the effect of Foreigners in the adverse selection component, a highly statistically significant difference once performed the Wald test.

All in all, the results of the Table 7 support the hypothesis that the short-term superior performance of Institutions, seconded by Foreigners, can be related to information advantage, as reflected in the short-term performance measures reported in Tables 3 to 5. There is also some mild evidence that institutions do more informed trading than foreigners, reflected in a higher effect on the adverse selection spread component.

\section{Conclusions.}

This paper investigates the differential performance of foreigners, institutions and individuals in the Colombian Stock Market. The results consistently show that institutions are the better performers, both in terms of trade execution as well as in terms of returns in different horizons: the very short term (daily), a month and a year. This advantage can be related to superior information, as detected in increasing adverse selection components of the bid-ask spread in the weeks where Institutions are more actively trading. This is consistent with two notions: First, institutions are more professional, savvy and well informed investors that individuals. Second, Locals are better informed than foreigners, which is one of the main explanations of the Home bias puzzle. As expected, in short term performance Institutions have a positive performance particularly in the largest stocks. Interestingly, Institutions also do better in long term performance mostly because of the stock they avoid or sell than for the stocks they buy or hold.

Foreigners come in second place. They appear to be the worst trade executers, which has already been reported by the literature. However, in most return measures they appear to have an edge over 
local individuals in terms of returns measured over a day, a month and a year, and in no case individuals do better than foreigners. Again, this shows that institutions do better than individuals, since Foreigners are mostly International Funds.

The results here presented reconcile some the contradictory findings of the literature. The question of who has the better performance in an emerging market can be answered differently depending on the context. Foreigners are clearly the worst executers of trades on a day by day basis. Moreover, when comparing performance of Institutions, Locals are clearly superior to Foreigners. When comparing the two groups of Locals, Institutions are unambiguously superior. However, if we pooled together the two types of Local agents, Foreigners might prove to have better performance, simply because local individuals do most of the transactions.

The most important question to be explored in this line of research is the nature of information advantage of the three types of investors. Is the local institution advantage firm specific? Country macro specific? Are foreigners better informed in terms of international financial and macro variables? Do individual possess any advantage on speculative stocks?. We also leave for future studies to compare the differential performance of short-term institutions (e.g. brokerage firms) vs long term institutions (e.g., Mutual and Pension funds) in the same line discussed in this study.

\section{References}

Agarwal, S., Faircloth, S., Liu, C., \& Ghon Rhee, S. (2009). Why do foreign investors underperform domestic investors in trading activities? Evidence from Indonesia. Journal of Financial Markets, 12(1), 32-53. 
Agudelo, D. A., Giraldo, S., \& Villarraga, E. (2015). Does PIN measure information? Informed trading effects on returns and liquidity in six emerging markets. International Review of Economics and Finance, 39, 149-161.

Ahn, H.-J., Cai, J., Hamao, Y., \& Ho, R. Y. (2002). The components of the bid-ask spread in a limit-order market: evidence from the Tokyo Stock Exchange. Journal of Empirical Finance, 9(4), 399-430.

Barber, B. M., Lee, Y. T., Liu, Y. J., \& Odean, T. (2009). Just how much do individual investors lose by trading. Review of Financial Studies, 22(2), 609-632.

Barber, B. M., Odean, T., \& Zhu, N. (2008). Do Retail Trades Move Markets? Review of Financial Studies, 22(1), 151-186.

Bowe, M., Hyde, S., \& Mcfarlane, L. (2013). Duration , trading volume and the price impact of trades in an emerging futures market. Emerging Markets Review, 17, 89-105.

Brennan, M. J., \& Cao, H. H. (1997). International Portfolio Investment Flows. Journal of Finance, 52(5), 1851-1880.

Chan, K., Menkveld, A. J., \& Yang, Z. (2008). Information asymmetry and asset prices: Evidence from the China foreign share discount. Journal of Finance, 63(1), 159-196.

Chen, Y., \& Gau, Y. (2014). Asymmetric responses of ask and bid quotes to information in the foreign exchange market. Journal of Banking and Finance, 38, 194-204.

Chen, Z., Lin, W. T., Ma, C., \& Zheng, Z. (2013). The Impact of Individual Investor Trading on Stock Returns. Emerging Markets Finance and Trade, 49(s3), 62-69. 
Choe, H., Kho, B.-C., \& Stulz, R. M. (2005). Do Domestic Investors Have an Edge? The Trading Experience of Foreign Investors in Korea. Review of Financial Studies, 18(3), 795-829.

De Cesari, A., Espenlaub, S., \& Khurshed, A. (2011). Stock repurchases and treasury share sales: Do they stabilize price and enhance liquidity? Journal of Corporate Finance, 17(5), 1558-1579.

Dvořák, T. (2005). Do Domestic Investors Have an Information Advantage? Evidence from Indonesia. Journal of Finance, 60(2), 817-839.

Easley, D., Engle, R. F., O’Hara, M., \& Wu, L. (2008). Time-Varying Arrival Rates of Informed and Uninformed Trades. Journal of Financial Econometrics, 6(2), 171-207.

Easley, D., Hvidkjaer, S., \& O’Hara, M. (2010). Factoring Information into Returns. Journal of Financial and Quantitative Analysis, 45(02), 293-309.

Easley, D., \& O’Hara, M. (1992). Time and the Process of Security Price Adjustment. Journal of Finance, 47(2), 577-606.

Eom, K. S., Ok, J., \& Park, J. (2007). Pre-trade transparency and market quality. Journal of Financial Markets, 10, 319-341.

Ferreira, M. a;, Matos, P., \& Pereira, J. (2009). Do Foreigners Know Better ? A Comparison of the Performance of Local and Foreign Mutual Fund Managers. Working Paper.

Glosten, L. R., \& Milgrom, P. R. (1985). Bid, ask and transaction prices in a specialist market with heterogeneously informed traders. Journal of Financial Economics, 14(1), 71-100. 
Grinblatt, M., \& Keloharju, M. (2000). The investment behavior and performance of various investor types: a study of Finland's unique data set. Journal of Financial Economics, 55(1), $43-67$.

Grullon, G., Kanatas, G., \& Weston, J. P. (2004). Advertising, Breadth of Ownership, and Liquidity. Review of Financial Studies, 17(2), 439-461.

Hasbrouck, J. (1991). Measuring the information content of stock trades. The Journal of Finance, 46(1), 179-208.

Hau, H. (2001). Location Matters : An Examination of Trading Profits. Journal of Finance, 56(5), 1959-1983.

Hendershott, T., \& Moulton, P. C. (2011). Automation, speed, and stock market quality: The NYSE’s Hybrid. Journal of Financial Markets, 14(4), 568-604.

Huang, R. D., \& Shiu, C. (2009). Local Effects of Foreign Ownership in an Emerging Financial Market: Evidence from Qualified Foreign Institutional Investors in Taiwan. Financial Management, 567-602.

Huang, R. D., \& Stoll, H. R. (1997). The Components of the Bid-Ask Spread : A General Approach. Review of Financial Studies, 10(4), 995-1034.

Jong, F. De, Nijman, T., \& Rsell, A. (1996). Price effects of trading and components of the bid-ask spread on the Paris Bourse. Journal of Empirical Finance, 3, 193-213.

Kaniel, R, Gideon Saar, and Sheridan Titman. 2008. "Individual Investor Trading and Stock Returns. Journal of Finance, 63(1), 273-310. 
Kyle, A. S. (1985). Continuous Auctions and Insider Trading. Econometrica, 53(6), 1315-1335.

Lee, C. M. ., \& Ready, M. J. (1991). Inferring Trade Direction from Intraday Data. Journal of Finance, 46(2), 733-746.

Lee, Y., Liu, Y., Roll, R., \& Subrahmanyam, A. (2004). Order Imbalances and Market Efficiency: Evidence from the Taiwan Stock Exchange. Journal of Financial and Quantitative Analysis, 39(2), 327-341.

Lee, Y.-T., Lin, J.-C., \& Liu, Y.-J. (1999). Trading patterns of big versus small players in an emerging market: An empirical analysis. Journal of Banking \& Finance, 23(5), 701-725.

Lei, Q., \& Wu, G. (2005). Time-varying informed and uninformed trading activities. Journal of Financial Markets, 8, 153-181.

Madhavan, A., Richardson, M., \& Roomans, M. (1997). Why do Security Prices Change? A Transaction-Level Analysis of NYSE Stocks. Review of Financial Studies, 10(4), 1035-1064.

Park, T.-J., Lee, Y., \& Song, K. "Roy." (2014). Informed trading before positive vs. negative earnings surprises. Journal of Banking \& Finance, 49, 228-241. 
Table 1. Summary statistics of trading activity by type of investor and size quartile.

Average trading Size (in US thousands)

\begin{tabular}{|c|c|c|c|c|c|c|c|c|c|}
\hline Size & $\begin{array}{l}\text { Total of operations } \\
\quad \text { (thousands) }\end{array}$ & $\begin{array}{l}\text { Total traded } \\
\text { value } \\
\text { (USD millions) }\end{array}$ & $\begin{array}{c}\text { Average } \\
\text { trading Size } \\
\text { (in thous. US ) } \\
\end{array}$ & $\begin{array}{c}\text { Total of } \\
\text { operations } \\
\text { (thousands) }\end{array}$ & $\begin{array}{l}\text { Total traded } \\
\text { value } \\
\text { (USD millions) }\end{array}$ & Mean & t-test $>$ Foreigners & \multicolumn{2}{|c|}{$\begin{array}{l}\text { t-test }>\text { Local } \\
\text { Individuals }\end{array}$} \\
\hline Quartile: & \multicolumn{3}{|c|}{ Total Sample } & \multicolumn{6}{|c|}{ Local Institutions } \\
\hline Total & 9,289 & 238,000 & 92.85 & 3,189 & 125,000 & 35.71 & $9.283 * * *$ & 66.109 & $* * *$ \\
\hline 4 & 4,540 & 139,000 & 107.41 & 1,642 & 75,100 & 43.91 & $7.581 * * *$ & 44.591 & $* * *$ \\
\hline 3 & 2,195 & 56,900 & 90.23 & 768 & 30,000 & 38.62 & $5.631 * * *$ & 46.559 & $* * *$ \\
\hline 2 & 1,235 & 21,500 & 69.58 & 414 & 11,300 & 34.76 & $3.008 * * *$ & 19.136 & $* * *$ \\
\hline 1 & 1,320 & 20,800 & 66.41 & 366 & 8,370 & 21.33 & 0.532 & 20.848 & $* * *$ \\
\hline
\end{tabular}

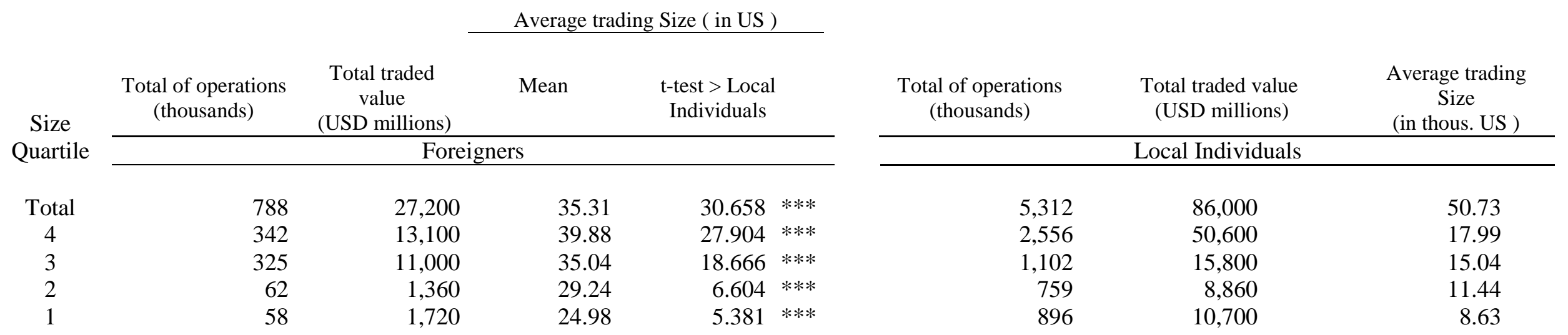

This table reports the summary statistics of trading activity in the Colombian stock exchange from 1-Jan-2007 to 30-May-2014, by different types of investors: summarized by quartiles market capitalizations. Based on data provided by the local exchange (BVC). A sample two-tailed t-test is presented to compare on the equality of average trading sizes between types of investor. *,**,***: Statistical significant at the $10 \%, 5 \%$ and $1 \%$, respectively. 
Table 2. Average trading cost in buys and sells by type of investor and size quartile.

\begin{tabular}{|c|c|c|c|c|c|c|c|c|c|c|c|c|c|c|c|c|c|c|c|}
\hline \multirow[b]{3}{*}{ Quartile } & \multirow[b]{3}{*}{$\begin{array}{c}\text { Average trades per } \\
\text { day }\end{array}$} & \multicolumn{3}{|c|}{ Buys } & \multicolumn{3}{|c|}{ Sales } & \multicolumn{3}{|c|}{ Buys } & \multicolumn{3}{|c|}{ Sales } & \multicolumn{3}{|c|}{ Buys } & \multicolumn{3}{|c|}{ Sales } \\
\hline & & $\mathrm{N}$ & Mean & & $\mathrm{N}$ & Mean & & $\mathrm{N}$ & Mean & & $\mathrm{N}$ & Mean & & $\mathrm{N}$ & Mean & & $\overline{\mathrm{N}}$ & Mean & \\
\hline & & & & Local I & utions & & & & & Fore & & & & & & $\mathrm{cal} \mathrm{Ir}$ & iduals & & \\
\hline Total & 360 & 47,200 & $-0.01 \%$ & $* * *$ & 46,257 & $-0.03 \%$ & $* * *$ & 27,231 & $0.09 \%$ & $* * *$ & 23,526 & $0.07 \%$ & $* * *$ & 51,721 & $-0.10 \%$ & $* * *$ & 53,037 & $-0.02 \%$ & $* * *$ \\
\hline 4 & 198 & 11,760 & $-0.02 \%$ & $* * *$ & 11,732 & $-0.02 \%$ & $* * *$ & 8,863 & $0.08 \%$ & $* * *$ & 7,801 & $0.06 \%$ & $* * *$ & 12,109 & $-0.07 \%$ & $* * *$ & 12,206 & $-0.02 \%$ & $* * *$ \\
\hline 3 & 66 & 15,367 & $-0.03 \%$ & $* * *$ & 15,294 & $-0.04 \%$ & $* * *$ & 10,681 & $0.09 \%$ & $* * *$ & 9,156 & $0.06 \%$ & $* * *$ & 16,400 & $-0.09 \%$ & $* * *$ & 16,587 & $-0.04 \%$ & $* * *$ \\
\hline 2 & 53 & 9,517 & $0.02 \%$ & $* * *$ & 9,138 & $-0.03 \%$ & $* * *$ & 3,765 & $0.08 \%$ & $* * *$ & 3,126 & $0.06 \%$ & $* * *$ & 10,446 & $-0.11 \%$ & $* * *$ & 10,941 & $-0.01 \%$ & $* *$ \\
\hline 1 & 44 & 10,556 & $0.01 \%$ & & 10,093 & $-0.04 \%$ & $* * *$ & 3,922 & $0.13 \%$ & $* * *$ & 3,443 & $0.10 \%$ & $* * *$ & 12,766 & $-0.13 \%$ & $* * *$ & 13,303 & $-0.01 \%$ & $* *$ \\
\hline
\end{tabular}

This table presents the results of average of daily trading cost in both buys [1], and sells [2], measured against the daily value weighted average price, for the three types of agents, the whole sample and four quartiles of size. For each measure the number of observations $\mathrm{N}$, the mean and statistical significance are reported. Based on data provided by Colombian stock exchange (BVC) from 1-Jan-2007 to 30-May-2014 *, **, ***: Statistical significant at the 10\%, $5 \%$ and $1 \%$, respectively. 
Table 3. Daily Performance Measure by type of investor and size quartile.

\begin{tabular}{|c|c|c|c|c|c|c|c|c|}
\hline \multirow[b]{2}{*}{$\begin{array}{r}\text { Size } \\
\text { Quartile }\end{array}$} & \multirow[b]{2}{*}{$\begin{array}{c}\text { Average trades } \\
\text { per day }\end{array}$} & $\mathrm{N}$ & Mean & $\mathrm{N}$ & Mean & & $\mathrm{N}$ & Mean \\
\hline & & Loca & Institutions & \multicolumn{3}{|c|}{ Foreigners } & \multicolumn{2}{|c|}{ Local Individuals } \\
\hline Total & 360 & 52,100 & $0.01 \%$ & 52,100 & $0.00 \%$ & & 52,100 & $-0.03 \%$ \\
\hline 4 & 198 & 12,159 & $0.08 \% * * *$ & 12159 & $0.03 \%$ & $* *$ & 12,159 & $-0.10 \% * * *$ \\
\hline 3 & 66 & 16420 & $0.00 \%$ & 16,420 & $0.05 \%$ & $* * *$ & 16420 & $-0.04 \% * * *$ \\
\hline 2 & 53 & 10,670 & $-0.08 \%$ & 10,670 & $-0.11 \%$ & & 10,670 & $0.06 \%$ \\
\hline 1 & 44 & 12,851 & $0.03 \%$ & 12,851 & $-0.02 \%$ & & 12,851 & $-0.03 \%$ \\
\hline
\end{tabular}

This table presents the results of the simple daily performance measure [3], for the three types of agents, the whole sample and four quartiles of size. The number of observations $\mathrm{N}$, the mean and statistical significance are reported. Based on data provided by Colombian stock exchange (BVC) from 1-Jan2007 to 30-May-2014*, **, ***: Statistical significant at the $10 \%, 5 \%$ and 1\%, respectively. 
Table 4. Daily Net profit Measure 1 by type of investor and size quartile.

\begin{tabular}{|c|c|c|c|c|c|c|c|c|c|c|}
\hline \multirow[b]{2}{*}{$\begin{array}{r}\text { Size } \\
\text { Quartile }\end{array}$} & \multirow[b]{2}{*}{$\begin{array}{c}\text { Average } \\
\text { trades per day }\end{array}$} & $\mathrm{N}$ & \multicolumn{2}{|c|}{ Mean } & $\mathrm{N}$ & \multicolumn{2}{|c|}{ Mean } & $\mathrm{N}$ & \multicolumn{2}{|c|}{ Mean } \\
\hline & & \multicolumn{3}{|c|}{ Local Institutions } & \multicolumn{3}{|c|}{ Foreigners } & \multicolumn{3}{|c|}{ Local Individuals } \\
\hline Total & 360 & 52,100 & $0.03 \%$ & $* * *$ & 51,204 & $0.03 \%$ & & 52,100 & $-0.07 \%$ & $* * *$ \\
\hline 4 & 198 & 12,159 & $0.05 \%$ & $* * *$ & 12,159 & $-0.01 \%$ & & 12,159 & $-0.10 \%$ & $* * *$ \\
\hline 3 & 66 & 16,420 & $0.01 \%$ & & 15,524 & $0.08 \%$ & $* *$ & 16,420 & $-0.06 \%$ & $* * *$ \\
\hline 2 & 53 & 10,670 & $0.06 \%$ & $* * *$ & 10,670 & $0.03 \%$ & & 10,670 & $-0.10 \%$ & $* * *$ \\
\hline 1 & 44 & 12,851 & $0.02 \%$ & $*$ & 12,851 & $0.03 \%$ & & 12,851 & $-0.03 \%$ & $* *$ \\
\hline
\end{tabular}

This table presents the results of the Daily Net profit Measure 1 [4], for the three types of agents, the whole sample and four quartiles of size. The number of observations N, the mean and statistical significance are reported. Based on data provided by Colombian stock exchange (BVC) from 1-Jan-2007 to 30May- $2014 *, * *, * * *$ : Statistical significant at the $10 \%, 5 \%$ and $1 \%$, respectively. 
Table 5. Daily Net profit Measure 2 by type of investor and size quartile.

\begin{tabular}{|c|c|c|c|c|c|c|c|c|c|c|}
\hline \multirow{3}{*}{$\begin{array}{r}\begin{array}{r}\text { Size } \\
\text { Quartile }\end{array} \\
\text { Total }\end{array}$} & \multirow[b]{2}{*}{$\begin{array}{c}\text { Average trades } \\
\text { per day }\end{array}$} & \multicolumn{3}{|c|}{ Mean } & $\mathrm{N}$ & \multicolumn{2}{|c|}{ Mean } & $\mathrm{N}$ & \multicolumn{2}{|c|}{ Mean } \\
\hline & & \multicolumn{3}{|c|}{ Local Institutions } & \multicolumn{3}{|c|}{ Foreigners } & \multicolumn{3}{|c|}{ Local Individuals } \\
\hline & 360 & 42330 & $0.04 \%$ & *** & 17535 & $-0.27 \%$ & $* * *$ & 49012 & $-0.02 \%$ & $* *$ \\
\hline 4 & 44 & 11343 & $0.06 \%$ & $* * *$ & 6611 & $-0.23 \%$ & $* * *$ & 12002 & $-0.06 \%$ & $* * *$ \\
\hline 3 & 53 & 14417 & $0.04 \%$ & $* * *$ & 7566 & $-0.25 \%$ & $* * *$ & 15862 & $0.01 \%$ & \\
\hline 2 & 66 & 7824 & $0.06 \%$ & $* *$ & 1611 & $-0.25 \%$ & & 9355 & $-0.05 \%$ & $* *$ \\
\hline 1 & 198 & 8746 & $0.00 \%$ & & 1747 & $-0.50 \%$ & * & 11793 & $0.01 \%$ & \\
\hline
\end{tabular}

This table presents the results of the Daily Net profit Measure 2 [5], for the three types of agents, the whole sample and four quartiles of size. The number of observations N, the mean and statistical significance are reported. Based on data provided by Colombian stock exchange (BVC) from 1-Jan-2007 to 30May-2014.*,**,***: Statistical significant at the $10 \%, 5 \%$ and $1 \%$, respectively. 


\section{Table 6. Performance of portfolios formed on monthly net buy quartiles by type of investor}

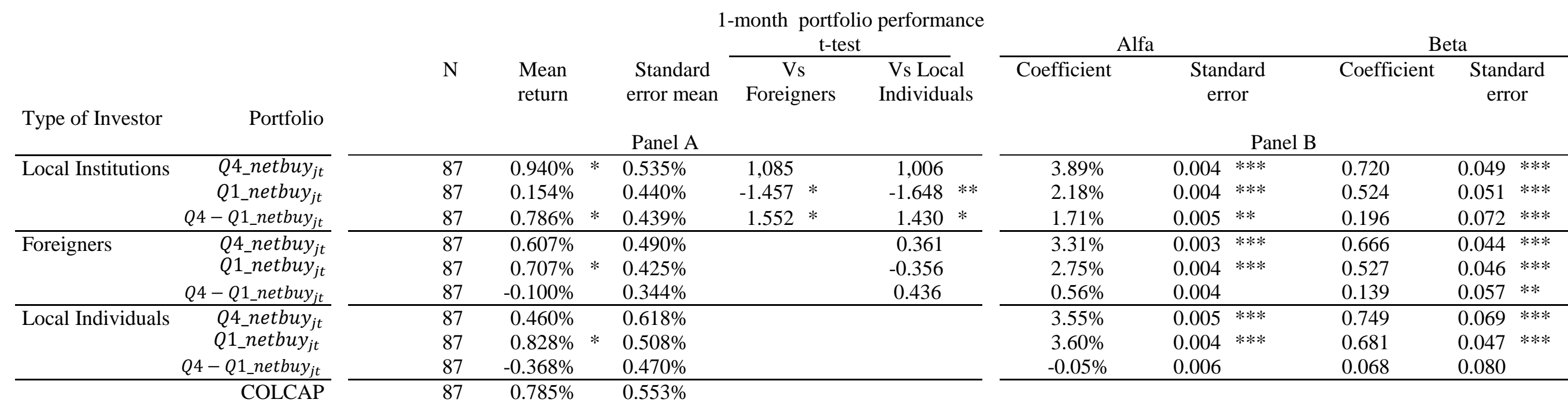

12-month portfolio performance

\begin{tabular}{|c|c|c|c|c|c|c|c|c|c|}
\hline \multirow{4}{*}{ Type of Investor } & \multirow{4}{*}{ Portfolio } & \\
\hline & & \multirow{3}{*}{$\mathrm{N}$} & \multirow{3}{*}{$\begin{array}{l}\text { Mean } \\
\text { return }\end{array}$} & \multirow{2}{*}{\multicolumn{2}{|c|}{$\begin{array}{l}\text { Standard } \\
\text { error mean }\end{array}$}} & \multicolumn{4}{|c|}{ t-test } \\
\hline & & & & & & \multirow{2}{*}{\multicolumn{2}{|c|}{$\begin{array}{c}\mathrm{Vs} \\
\text { Foreigners }\end{array}$}} & \multicolumn{2}{|c|}{$\begin{array}{l}\text { Vs Local } \\
\text { Individuals }\end{array}$} \\
\hline & & & & \multicolumn{4}{|c|}{ Panel C } & & \\
\hline \multirow[t]{3}{*}{ Local Institutions } & $\overline{Q 4 \_n e t b u y_{j t}}$ & 76 & $0.618 \%$ & $* *$ & $0.222 \%$ & 0.204 & & 1.954 & $* *$ \\
\hline & $Q 1 \_n e t b u y_{j t}$ & 76 & $0.185 \%$ & & $0.147 \%$ & -1.975 & $* *$ & -3.783 & $* * *$ \\
\hline & $Q 4-Q 1 \_n e t b u y_{j t}$ & 76 & $0.433 \%$ & $* *$ & $0.152 \%$ & 1.455 & $*$ & 3.287 & $* * *$ \\
\hline \multirow[t]{3}{*}{ Foreigners } & $\overline{Q 4 \_n e t b u y_{j t}}$ & 76 & $0.598 \%$ & $* *$ & $0.207 \%$ & & & 1.701 & $* *$ \\
\hline & $Q 1 \_n e t b u y_{j t}$ & 76 & $0.444 \%$ & $* *$ & $0.185 \%$ & & & -2.071 & \\
\hline & $Q 4-Q 1 \_n e t b u y_{j t}$ & 76 & $0.154 \%$ & & $0.134 \%$ & & & 2.242 & \\
\hline \multirow[t]{4}{*}{ Local Individuals } & $\overline{Q 4 \_n e t b u y_{j t}}$ & 76 & $0.390 \%$ & $*$ & $0.220 \%$ & & & & \\
\hline & $Q 1 \_n e t b u y_{j t}$ & 76 & $0.705 \%$ & $* * *$ & $0.208 \%$ & & & & \\
\hline & $Q 4-Q 1 \_n e t b u y_{j t}$ & 76 & $-0.315 \%$ & $* *$ & $0.124 \%$ & & & & \\
\hline & COLCAP & 76 & $0.652 \%$ & $* * *$ & $0.194 \%$ & & & & \\
\hline
\end{tabular}


This table describes the performance of the equally weighted portfolios formed by the monthly top $\left(Q 4 \_n e t b u y_{j t}\right)$ and bottom quartile $\left(Q 1 \_n e t b u y_{j t}\right)$ stocks by monthly net buy for each of the three type of investors. The performance of a portfolio long in the top quartile and short in the bottom one, Q4-Q1_netbuy ${ }_{j t}$ is also reported. In Panels A and B the performance is computed from monthly returns of the portfolios rebalanced at the end of the month. In Panel C the performance is computed as the effective monthly return of the portfolios in a 12-month period, without rebalancing. Panel A and C report the summary statistics and comparisons between types of investors using a two-tailed t-test. Panel B reports the results of the regression of monthly excess returns of each portfolio against the excess return of the market index COLCAP, using the TIB (Tasa interbancaria) as the risk free rate. The paired two-tailed t-test in panels A and C check if the mean return of the portfolio in the row is higher or lower than the mean return of the portfolio in the column. Based on data provided by Colombian stock exchange (BVC) from 1-Jan-2007 to 30-May-2014. *, **, ***: Statistical significant at the 10\%, 5\% and 1\%, respectively. 


\section{Table 7. Regressing the implied spread and its adverse selection component against trading intensity by type of investor}

Dependent variable:

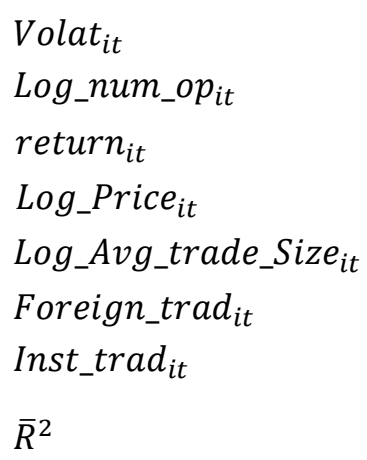

\section{Panel A : Fixed Effects panel data}

Implied_spread $_{i t}$

$A d v_{-} s e l e c_{-} c o m p_{i t}$

7.339
$-0.107 *$
$-0.978 *$
$80.334 * *$
-7.465
23.568
-2.736
0.280
2,327
1.280

Panel B: Seemingly Unrelated regressions

Implied_spread $_{i t} \quad A d v_{-}$selec_comp $p_{i t}$

-765.666
-0.062 ***
2.994
$8.711 * * *$
-0.297
$-32.400 *$
-16.274

711.817

$-0.016 * * *$

$-0.018$

$-0.305 * *$

0.190

$4.125 * *$

$-16.274$

$10.695 * * *$

2327

1.330

This table reports the results of panel data and SUR models regressing the implied spread and its adverse selection component against trading intensity by type of investor, following specifications [7] and [8]. Panel A presents the results of fixed effects panel data models, Panel B for seemingly unrelated regressions (SUR). Econometrical models are estimated in a stock-week basis, against bid-ask spread determinants and two measures of trading intensity by foreigners, Foreign_trad it $_{\text {and local institutions, Instit_trad }}$. The last row presents the result of a Wald test on the difference between the two coefficients of trading intensity. Implied spreads and adverse selection components are estimated in a stock-week basis following the MRR model that uses a GMM specification [6] based on transaction prices. Panel data models are estimated with fixed effects and using PCSE (panel-corrected standard error) corrections for auto and cross-correlation and heteroscedasticity. Based on transaction data taken from Bloomberg data and daily data by Colombian stock exchange (BVC) from 23-Aug-2010 to 31-Aug-2012.*, **, ***: Statistical significant at the 10\%, 5\% and 1\%, respectively. 